\title{
DEVELOPING A GREEN AGRICULTURAL EXTENSION THEORY
}

\author{
K. REZAEI-MOGHADDAM \& E. KARAMI \\ Department of Agricultural Extension, College of Agriculture, Shiraz University, Shiraz, Iran.
}

\section{ABSTRACT}

The purpose of this paper is to use the case of Iran to examine the basic premises of the ecological modernization (EM) and de-modernization (DM) theories with regard to agricultural extension policies to generate a green theory for agricultural extension. We argue that extension activities do not promote sustainability, so that technologies presented by extension are unsustainable. It is necessary to rethink seriously the activities, missions, and efforts of extension. It can be argued that agricultural extension should be reinvented. Two competing polar conceptual paths for agricultural extension are presented by EM and DM theories. These two paths are used to reconstruct the theoretical basis of agricultural extension.

Key words: de-modernization, ecological modernization, green extension theory, Iran.

\section{INTRODUCTION}

Agricultural extension is a term with many and varying connotations. By way of summary, Roling [1] formulates a definition of extension: 'A professional communication intervention deployed by an institution to induce change in voluntary behaviors with a presumed public or collective utility'. Almost all definitions emphasize that extension is a premeditated, planned, programmed, systematically designed, goal-directed, and purposeful activity. It is an intervention. One of the most intriguing aspects of extension is its contradictory nature. It is an instrument of premeditated and deliberate intervention to achieve the intervener's goals, which can only be effective by inducing voluntary change and hence by satisfying client goals [1]. Extension operates at the interface of these two types of intentionalities and the hallmark of extension professionalism and of its strategic deployment lies in handling of contradiction.

Diffusion theory is the theoretical base of agricultural extension. Traditionally, under the diffusion approach, the mission of extension has been to increase agricultural production and productivity through the transfer of relevant knowledge and information, and the offering of technical and economic advices. Today, there are practical challenges and theoretical reasons for adapting and widening the mission of extension [2]. However, analyses of extension services show that its activities based on the objective of only increasing production has produced negative impacts such as environmental degradation, poverty, uneven development, and inequality [3, 4]. Agricultural extension as a professional practice is changing, or should change, considerably.

The purpose of this paper is to use the case of Iran to examine the basic premises of the ecological modernization (EM) and de-modernization (DM) theories with regard to agricultural extension policies to provide a theoretical base for sustainable agricultural extension activities. We identify EM and DM theories based on their key elements and then introduce a brief history of agricultural extension in Iran. The application of EM and DM theories to agricultural extension problems is then presented followed by its application to theorize agricultural extension in Iran and presenting dimensions of a green extension theory.

2 DEFINING DE-MODERNIZATION AND ECOLOGICAL MODERNIZATION THEORIES The works of Otto Ullrich (Germany), Ivan Illich (France), Fritz Schumacher (UK), Rudolf Bahro (Germany), Andre Gorz (France), Bary Commoner (USA), Hans Achterhuis (the Netherlands), 
Murray Bookchin (USA) and other 'theorists of counter-productivity' were very influential within the environmental movement in the 1970s. They claimed that modern large-scale mega-technology should be seen as one of the main causes of environmental disruption instead of a factor which can contribute to its solution. Thus, a movement away from modern industrial technology is a precondition to the improvement of society's environmental quality. These theorists maintain that a radical movement away from advanced, complex technologies remains the only viable and feasible strategy for overcoming the ecological crisis. Indeed, they insist on the need for fundamental alterations in values and structures and demanding deep and systematic changes in philosophy and tactics [5]. Because of their insisting on the partial or total dismantling of the industrial system, the counter-productivity stream of thought has been referred to as 'de-modernization' theories.

EM theory was first developed primarily in a small group of western European countries, notably Germany, the Netherlands, and the United Kingdom (UK). Social scientists such as Joseph Huber, Martin Janicke, Volker Von Prittwitz, Udo Simonis, and Klaus Zimmermann (Germany), Gert Spaargaren, Maarten Hajer, and Arthur P.J. Mol (the Netherlands), and Albert Weale, Maurie Cohen, and Joseph Murphy (UK) made substantial contributions to this scholarship. Joseph Huber, who should be acknowledged as the father of EM theory [6], differentiates three analytical categories or spheres in analyzing modern society. Apart from the industrial system (or technosphere) and the life world (or sociosphere), which are more or less in line with other social theories, Huber introduces a third sphere: nature, or the biosphere. According to Huber, the main problems in the present society are related to the colonization of both the sociosphere and the biosphere by the industrial system (or technosphere). These problems, interpreted as structural design faults of the industrial system, can be overcome by an ecosocial restructuring of the technosphere, which Huber calls EM. The industrial, rather than capitalist or bureaucratic, character of modernity is where the EM theory differs from the DM theory [7].

EM suggests that policies for economic development and environmental protection can be combined with synergistic effect. Rather than perceiving the goals of environmental protection to be a brake on development, EM promotes the application of stringent environmental policy as positive influence on economic efficiency and technological innovation [8]. Indeed, the basic claim of EM is that modern society possesses a capability to carry through an institutional reflexivity and to build a capacity in society enabling it to handle its ecological crisis [9].

Rezaei-Moghaddam et al. [10] presented a comparison of the core features of DM and EM theories. Their analysis has been designed to represent as much as possible the polar positions of DM and EM. All the components of the two theories have been organized into the following six major dimensions: de-industrialization versus hyper-industrialization, traditional technology versus modern technology, social economy versus ecological economy, rejecting the important role of state versus strong modern environmental state, radical environmentalism versus reform ideology, and not-changing discourses versus changing discourses.

\section{A BRIEF HISTORY OF AGRICULTURAL EXTENSION IN IRAN}

From the perspective of agricultural development theory, the history of agricultural development in Iran can be divided into three major periods [10]:

- Period of development without theory (prior to 1960)

- Period of Modernization theory (1960-1980)

- Period of crisis in development theory (1980 to present) 
Each period has distinct characteristics in terms of efficiency, demand for food, theoretical perspective, environmental problems, awareness about environmental problems, and also theory and practice of agricultural extension. A description of agricultural extension in each period follows.

\subsection{Period of no formal extension organization}

Although the beginning of this period goes many years back, it was ended by the establishment of the Agricultural Extension Office in the Ministry of Agriculture in 1953. Up to 1953, government had neither followed a program, nor established a specific organization for extension of agricultural activities. There was no state responsibility for transfer of agricultural information. The only government consideration was from the officials' support shown by their interest. Farmers learned agricultural activities often from nature, direct and indirect experiences, and their parents. A few books related to agriculture and production of agricultural activities was published in this period [11]. Agricultural productivity was very low due to many factors, the most important of which were primitive farming practices and ignorance of farmers [12]. From an environmental perspective, this period could be called sustainable. Yet this sustainability was not achieved because of extension activities, in contrast, it appears that the lack of outsider's intervention resulted in sustainable agriculture but with low production. The production system was based on farmers' indigenous knowledge with no external inputs. During this period, the country with its low population density lived in relative poverty due to primitive agricultural practices.

\subsection{Establishment of formal agricultural extension service}

The biggest difference between this period and the previous was the establishment of a formal agricultural extension organization in the Ministry of Agriculture to support the agricultural production processes. The extension office was established in the Ministry of Agriculture in 1953. This office was promoted to the departmental level in 1959 with expanded activities [13]. New activities consisted of dissemination of new planting and harvesting procedures, land preparation, improved seeds, vegetation, improvement of husbandry and poultry, etc. A number of extension methods were used in this case [13].

The dominant development theory of this period was 'modernization' [10]. The central element of this theory is the metaphor of growth and the identification of growth with an idea of progress [14]. The main objective of agricultural extension in Iran was set, based on this theory. That is to say that the theoretical foundation of extension was based on diffusion of technologies. The objectives of extension services were frequently limited to the problem of increasing production. The agricultural extension strategy was to create a group of so-called 'progressive' farmers through whom new ideas and technologies could be diffused [15].

The beginning of this period was marked by the land reform of 1962. The land reform was perceived as a prerequisite to any effort to modernize the traditional, predominantly rural society of Iran. Different types of modern production systems were introduced to Iranian agriculture, including capitalist farm enterprises, farm corporations, rural modern cooperatives, and agribusinesses [16]. The personnel of the extension department took part in conducting administrative tasks related to land reform. Many specialists believed that this diverted the extension agents from their real tasks, goals, philosophy, and responsibilities [11, 12]. This period coincided with the so-called 'green revolution'. Transforming traditional agriculture called for a major shift in agricultural technologies and practices. Then, the transfer of technology became the dominant agricultural development model 
for extension practitioners. Lack of sufficient linkage between extension and the research organizations has been an obstacle for extension services. The negative impact of agricultural extension activities on environmental aspects has been discussed by many specialists indicating that the technologies presented by extension do not promote sustainability; hence, environmental degradation has been intensified [4, 17]. The study of Karami and Hayati [18] in Fars province revealed that farmers start to compete with each other in order to extract more water from their boreholes. So farmers use their water resources based on a greed behavior. Lack of suitable agricultural extension services to increase farmers' knowledge and skills about appropriate water saving technologies exacerbates the status quo [18].

A nationwide survey conducted by Karami and Hayati [19] revealed that the attitude of extension agents, agricultural researchers, and extension experts towards sustainable agriculture were low. The need for dynamic framework for setting extension objectives in Iran is greatly felt, and the current theoretical frameworks are inadequate for setting extension objectives [20]. Karami [20] presented issues such as development perspective, sustainable development, agricultural knowledge systems (AKSs), agricultural non-knowledge systems and gender as the determinants of extension objectives in Iran. Karami [4] has questioned the sustainability of Iran's agricultural extension efforts. He has argued that the agricultural extension efforts in Iran have increased the gap between developed and undeveloped villages. The theory and practice of agricultural extension during this period has been criticized on different grounds. Considering the issue of social and environmental problems, modification of extension efforts is needed so that this important institution of agricultural development can promote a more sustainable form of agricultural development.

\subsection{Period of crisis in extension theory (1980 to present)}

The objective of agricultural extension in Iran during this period has been to increase economic growth and agricultural production. Increasing agricultural production through development and stimulation of technical innovations and advice, still remains an important concern for agricultural extension in Iran. But, in this period, there are new internal and external challenges that agricultural extension will have to meet if it wishes to play a role in future sustainable development. One of the most important challenges is increasing awareness and concern for environmental problems. Agricultural extension in Iran has been criticized sharply for its detrimental effects on the natural environment [17]. An additional challenge for extension is to alleviate poverty and to reduce the gap between different groups of farmers. The existing technical approaches to research and extension services are an inefficient way of improving farming systems, particularly for small farmers. The relationship among sustainability, poverty, and extension activities has been analyzed in Behbahan [17]. The findings of this study showed that extension activities are not promoting sustainability and poverty alleviation. Also, the technologies presented by extension agents are unsustainable. Technological deficiencies are considered a major obstacle in achieving the objective of agricultural production [21] and the environmental protection goals [10]. These are the reasons why we seriously need to rethink activities, missions, and efforts of extension. It can be argued that the agricultural extension in Iran should be reinvented. Although, diffusion theory as the theoretical basis of extension has been criticized $[4,15]$, the experts have failed to provide an alternative conceptual framework. Therefore, we argue that the contemporary agricultural extension theory is in crisis.

\section{NEW TRENDS FOR AGRICULTURAL EXTENSION IN IRAN}

The extension efforts for agricultural development have been criticized in Iran. The conventional development strategies are fundamentally limited in their ability to promote sustainable agricultural 
development in Iran [22]. Ghazinoory [23] argued that Iran is facing serious problems of pollution and devastation of the environment. He emphasized the urgency to adopt and implement a holistic and integrated cleaner production strategy for all of Iran. Karami [4] concluded that if extension efforts are to have a more sustainable impact, educating the agricultural extension workers about sustainable development will be the first step. Sustainable extension efforts will be characterized by balance, i.e., it should help farmers to balance yield and income, considering environmental quality and sustainability of production. In his opinion, the first question is simply how well informed are the extension personnel about the concept of sustainability? For example, what are their views on the relationship between humans and nature?

The literature on agricultural development and extension in Iran indicates that agricultural development theory is in crisis. Since the rise of concern for the environmental consequences of agriculture and increasing criticism of conventional agriculture, there seems to be a lack of theoretical basis for sustainable agricultural development [10]. Rezaei-Moghaddam et al. [10] argued that the EM and DM theories could be used to develop conceptual frameworks for agricultural development. The application of EM and DM to achieve sustainable agricultural development has been discussed in detail. Based on the DM theory, agricultural development issues become reduced to de-modernize agriculture by using indigenous practices to preserve the environment. Assuming that modern technology is the cause of all environmental problems, there is a tendency to transform conventional agriculture to traditional farming systems. It is assumed that a traditional agricultural system based on indigenous knowledge, technology, and social organization can maintain biological diversity and conserve natural resources. On the other hand, through the EM world-view, agricultural development can be defined as transformation of conventional agriculture to hypermodern agriculture. Advanced precision agriculture will protect the environment while helping to increase or at least maintain the productivity [10]. Based on Rezaei-Moghaddam et al. [10], conceptual path based on DM theory with great concern for environmental protection and less attention to increased production, does not seem to be a viable path to achieve sustainable agriculture. Rezaei-Moghaddam et al. [10] emphasized growing consensus over the need for a shift in paradigm if sustainable agriculture is to be realized. This paradigm shift in agriculture is a change from one way of thinking about agriculture to another. The primacy of values and attitudes in shifting the agricultural paradigm cannot be questioned. They argued that without strong dissatisfaction with 'the conventional agricultural paradigm' and favorable values and attitudes toward a 'sustainable agricultural paradigm', no paradigm shift can be realized. This rather prominent step towards sustainable agriculture seems to be taken for granted by EM- and DM-based sustainable agricultural theories [10].

In an attempt to provide an agenda for sustainable agricultural development, Rezaei-Moghaddam et al. [24] have developed two competing sustainable agricultural development models based on the general tenets of EM and DM theories. They depicted the attitudes of Agricultural Organization (Jehad-e-Keshavarzi) specialists of two southern provinces of Iran (Khuzestan and Fars provinces) regarding the basic premises of these models to provide a conceptual framework for sustainable agricultural development. They concluded that the present system of agriculture in Iran is far apart from the ideal system of agriculture. This discrepancy is of great importance, because it illustrates that future agriculture will have different characteristics than the present practices and that there are major areas that need to be changed. The agricultural specialists believe that we need to change toward sustainable agriculture [24]. This study indicated that the EM-based sustainable agricultural development model is perceived to be a more viable path to sustainable agricultural development in Iran than the DM-based model. In the specialists' attitude, three central premises of the EM-based sustainable agricultural development model, i.e., application of 'modern and clean-up technology', 'scientific knowledge', and attention to 'both production and environmental protection' in policies, 
are of great importance for ideal agriculture in Iran. They imply that ideal agriculture would seek to produce more while protecting the environment. Specialists' attitude supports the integration of increased productivity and protection of the environment. Indeed, the EM-based sustainable agricultural development model, which specialists believe to be a viable path to ideal agriculture in Iran, presumes that agricultural development policies can use clean-up technologies and appropriate research that besides increasing agricultural production, also conserves environmental quality. Therefore, in ideal agriculture in Iran, ecological and economic rationality are seen as having their own legitimacy in agricultural development. According to this study, policy making in agriculture, due to negative impacts of agricultural industrial practices, should be based on ecological restructuring of these practices (in order to achieve increased production and reduced degradation of the environment) [24].

Rezaei-Moghaddam and Karami [25] used the analytic hierarchy process (AHP) to reach a decision, regarding commitment to a theoretical base for sustainable agricultural development among stakeholders of agriculture in Fars province of Iran. Rural women, farmers, environmentalists, board members of rural cooperative and agricultural experts are the stakeholders of Fars province agriculture who were involved in the AHP decision process. The stakeholders identified nine criteria for sustainable agriculture. Stakeholders perceived sustainable agriculture to be economically profitable and socially and ecologically sound. Ecological criteria including wise use of resources, environmental protection, and product quality were the most important criteria for sustainable agricultural development. The results of this study indicated that the EM-based sustainable agricultural development model is more theoretically sound than the DM-based model for agricultural development in Iran [25].

The EM-based model identifies new trends for sustainable agricultural development and extension in Iran. It is concluded that the future path to sustainable agricultural development in Iran is EMbased. Evans et al. [26] state that the observed trends in agriculture could be viewed as part of a move toward EM. It appears that many of the trends with regard to food quality and safety, and environmental management also fit well into the EM-based model.

\section{WHAT IS AGRICULTURAL EXTENSION THEORY?}

Extension theory and practice have been evolving over time. On the whole, more effort has been put in refining practice than in refining theory. Royen [27] sums up the main elements of the extension process and their interconnectedness through systematic linkages. These elements include objectives, offerings (service, product, message), target groups, methods (communication, distribution), and organization (means) [27]. A review of literature by Roling [27] indicates that other people have also identified similar elements in the extension process. Thus, Kotler distinguishes the 'five Cs': cause (or objective), change agency (or organization/means), change target (groups), channels, and change strategy.

Agricultural extension is the central issue in formulating and disseminating knowledge, and in enabling farmers to become competent decision-makers. Extension, in general, is part of a larger system of protagonists who influence farmers' decisions. Such systems are known as 'agricultural knowledge systems'. In this system, extension is a sub-system of the larger system in which research and utilizers also form sub-systems. It was said that the two models from Royen and Kotler essentially consisted of attempts to transfer knowledge and technology from the research sub-system to the utilizer sub-system [28]. The role of extension in these two models is instrumental. As we have argued in the previous sections, the transfer of knowledge and technology seem to be inadequate to guide us in implementing the kind of change required. There is a general acceptance that the concept of AKS is not constructive with regard to the sustainable agriculture paradigm. 
Roling and Jiggins [29] argued that the conditions for sustainable agriculture are created in the socio-sphere through policy, institutional, and behavioral change. They call these conditions in the socio-sphere 'the ecological knowledge system' (EKS). EKS was introduced in response to a need for a knowledge system to transform agricultural paradigms. The main dimensions along which they examine the transformation to ecologically sound agriculture are ecologically sound practices, learning, facilitation, support institutions and networks, and conducive policy contexts. The five dimensions form a mutually interdependent and consistent whole, in which the nature of the ecologically sound practices makes special demands on learning, which in turn places special demands on facilitation, institutional support, and a conducive policy context. The EKS is fundamentally different from a knowledge system to support conventional agriculture [29]. This system includes new actors and different roles and tasks than traditional AKS. It requires new technologies, production systems, and farming practices, which tend to be more knowledge intensive [10].

Agricultural extension theory in the EKS looks at efforts to make agriculture more sustainable, both at the farm and higher system levels. It examines the implications of sustainable agriculture for land users and other stakeholders as social actors and goes on to analyze how conditions for change can be created. The main purpose of agricultural extension in this knowledge system is to help land users become experts at managing complex eco-systems in a sustainable manner. The management does not focus on instrumental control of eco-systems to optimize the value of key variables, but on adaptive and responsive management of diversity and complexity to optimize opportunities and outcomes.

\section{DISCUSSION: IMPLICATION OF EM TO THEORIZING GREEN AGRICULTURAL EXTENSION}

Considering the current crisis in agricultural extension theory, we believe that EM theory could be used to reconstruct the theoretical basis for agricultural extension in Iran and developing countries. In applying EM to the construction of a sustainable agricultural development theory, five dimensions of green extension theory including content, learning, negotiation, organization, and policy will be discussed.

\subsection{Content}

EM-based agricultural extension emphasizes that the only possible way out of the ecological crisis is by going further into the process of modernization. Through the EM world-view, agricultural development can be defined as the transformation of conventional agriculture to hypermodern agriculture. One alternative direction for agricultural development due to characteristics of the present age including increased population, decrease of area under cultivation, and stringent need for food quality and safety is more industrialization and modernization of agricultural production in a way as to combine increased productivity with better environmental performance [10]. EM-based agricultural extension promotes more use of industry and technology in organization of production and consumption of agricultural production. It is knowledge and technology intensive. Indeed, hypermodern agriculture involves addressing environmental problems primarily through the transformation of production via the development and application of more sophisticated technologies.

EM-based agricultural extension is based on the diffusion of modern and clean-up technologies. These technologies were understood to be those innovations which resulted in an 'improvement in environmental quality' [30]. Use of these technologies can decrease demands on natural systems and increase our ability to control the environmental consequences of production. The key to sustainable and sound agricultural growth is technology that produces little or no waste coupled with careful 
management to maximize efficiency and safety [10]. The goal of the clean technology is to spur and define environmentally innovative behavior [9]. Improved cost effectiveness coupled with environmental improvement is the theme behind preventative environmental strategies through the implementation of cleaner technologies [31]. Indeed, EM-based agricultural extension does rely on sophisticated technology to manage agricultural and production activities.

'Precision agriculture' technologies, based on information technology, constitute a new mission for EM-based extension. These embrace scientific knowledge (such as agronomic science) and its practical expression (machines, treatments, procedures, tools, supplies) [32]. Using these technologies, EM-based extension integrates a multidisciplinary approach involving agronomists in various fields, engineers, manufactures, and economists to achieve sustainable development. Agricultural extension systems based on EM can extend the ideas of precision agriculture into the application of precision horticulture, precision animal and aquaculture management, precision processing of agricultural products as well as precise management for the entire agricultural industry. The precision agriculture technologies allow farmers and other stakeholders to collect and document environmental variables which can then be used for greener management activities and to promote their environmental soundness to customers.

Biological pest control as an environmental technology is one of the critical components of sustainable agriculture. It contributes to food security, reduces pests, and conserves the environment. Biological pest control should therefore be high on the agenda of projects for its contribution to the development of developing countries.

\subsection{Learning}

Learning is an integral part of everyday life. In agricultural processes, learning may occur and/or be required on various fronts. For a long time, we have defined learning in agriculture as the adoption process, a farmer's encounter with an external innovation, first becoming aware of it, then gaining additional information, and finally becoming convinced to adopt or reject it. The context is thus the delivery of external - usually science-based - innovations to farmers as the potential users. Indeed, the change to ecologically sound agriculture is not comparable to the adoption of an add-on innovation, but a complex learning process which can take a few years. It has been likened to obtain a degree [29]. Therefore, the transformation not only involves a change in the farm in terms of the establishment of populations of natural enemies of local pests, the adaptation of crop rotation practices, the build up of soil organic matter, etc. (which may take a number of years in itself) but also, especially a transformation of people and institutions and policies.

Improving agricultural production and fostering development in agriculture is not just a matter of individuals receiving messages and adopting the right technologies, but has much more to do with altering inter-dependencies and coordination between various actors. In addition, we recognize new challenges, problems, and developments - some of which operate at a larger scale than before - that further complicate matters. Hence, the issues we are dealing with are not just agricultural or relating to farmers alone; they are concerned more broadly with human relations, forms of organization, economic and legal institutions, knowledge, or skills. Leeuwis and Van den Ban [2] argued that for purposes of arriving at coherent innovations (in rural change), it is clear that 'individual' learning does not suffice, but that simultaneous learning of interdependent stakeholders is needed. They emphasized the shift away from a focus on individual behavior change, and incorporating the idea that extension is about fostering new patterns of coordination. For this, several authors have coined the term 'social learning'. Roling describes 'social learning' as a key mechanism for arriving at more desirable futures and as a 'third way of getting things done' that stands in sharp contrast to the 
instrumental modes of thinking. More specifically, Roling defines social learning as 'a move from multiple to collective or distributed cognition' [2].

Ecologically sound agriculture is substantially learned as collective learning in small groups or 'field schools'. Discussion plays a key role in concept formation, in the development of the theory with which to anticipate on the basis of observation, in assessing external information, and in coping with the uncertainty of embarking on a new way of farming [29]. An important aspect of this learning is the power of 'discovery learning'. Carefully structured learning experiences, such as the agroecosystems analysis, seem to have an energizing and mobilizing effect. Discovery learning relies on engaging people in experimentation, observation, measurement, and so on, which allow people to draw their own conclusions [29].

Rural change and agricultural development often do not involve farmers alone. Moving to hypermodern agriculture requires learning new roles across a wide range of actors. A number of factors and processes help extension agents understand better whether learning takes place or not. It must recognize that learning takes effort, energy, and time. This means that learning can be considered 'a scarce resource' in the agricultural development processes. The initial task of extension agents is that farmers and other agricultural stakeholders experience environmental degradation as a problem. The clients of extension may regard this problem as serious and important, but may not experience the consequences personally. A slightly different issue is whether various groups are personally affected or not by the consequences of a problem. One important task of extension is to understand urgency to solve a problem. When farmers and other stakeholders feel there is an urgent need to solve environmental degradation, they are often motivated more to engage in learning.

The agricultural stakeholders must have some confidence that they can solve the problem, i.e. they must trust their own capabilities with regard to problem solving and/or have the idea that they will be supported effectively by others in finding and implementing solutions. Whenever such confidence is lacking, learning is less likely to occur. The extension agents should notice that the complexity of problems (such as environmental issues) is related to the level of learning required and indirectly affects the clients' motivation to learn. Finally, different stakeholders must reach an agreement on the nature and seriousness of the problem. If they are confronted with contradictory information in relation to environmental problems by extension agents, they may become confused and discouraged from dealing with it.

It is important for extension agents to realize that stakeholders and farmers may have encompassed different aspects of learning, and so for each aspect different types of information may be needed. Leeuwis and Van den Ban [2] identify the following aspects of learning that participants in a social learning process must go through: becoming aware, becoming interested/mobilized, becoming involved in active experiential (social) learning (in the context of negotiation) and establishing adopted practices and routines.

\subsection{Negotiation}

Human beings are all sharing a unique planet and are living in societies; so the problem of coexistence of people becomes important. Life in society can be described as inevitable and dynamic construction of coexistence. It is a fact of life that people have different value systems stemming from their different standpoints and that no single value system can be defined as superior to, or encompassing all other value systems. These different values may lead to divergent interests.

Agricultural development decision-making is becoming more pluralistic [25]. In recent years, participation has become a widely advocated methodological principle for intervention practice, and a range of participatory methodologies, methods, and techniques have been proposed to operationalize it. 
Participatory approaches have been increasingly advocated as effective decision-making processes to address complex environment and sustainable development issues [33]. We need to develop an approach towards participation that does not negate the significance of strategic actions and conflicts of interest, by somehow rendering them normatively undesirable. Rather, we need an approach that starts from the assumption that actors are likely to act strategically in relation to existing and emerging conflicts of interests, and then find ways of using this to solve societal problems. For the purpose of developing such an approach, negotiation theory can help to direct participatory trajectories as an alternative to the prevailing planning, decision-making, and social learning models.

The EM theory highlights enhanced participation processes and new corporate strategies [34]. It implies a partnership in which all agricultural actors cooperate in the restructuring of the current agricultural system. EM-based agricultural extension theory includes new actors and different roles and tasks than the traditional AKS. How can different actors coordinate these interests to develop agricultural programs to meet a set of often-conflicting objectives? Extension agents should take on a new role, and aspire to manage communication in processes that are somehow aimed to bring about new patterns of coordination. We think of such processes mainly in terms of negotiation. Agricultural extension needs an approach that starts from the assumption that the agricultural actors are likely to act strategically in relation to existing and emerging conflicts of interests, and then finds ways of using this to solve environmental problems.

Leeuwis [35] suggests 'integrative' negotiation as an approach for extension agents. Such an approach can bring a range of useful guidelines and insights into the current discourse on participation. In this approach, the agricultural actors develop new (and often wider) problem definitions and perceptions on the basis of a creative-collective (social) learning process, resulting in the identification of so-called 'win-win' solutions. This coincides with the aspirations usually associated with participatory intervention. He suggests a number of tasks for extension agents to facilitate integrative negotiations [35]:

- Preparing the process by exploratory analysis of conflicts, problems, relations, practices, etc. in a historical perspective and selecting participants for extension projects.

- Reaching and maintaining process agreements. This includes activities such as creating an agreed-upon code of conduct and provisional agenda or reaching agreement with procedures, methodologies, etc.

- Joint exploration and situation analysis. This includes achieving such goals/objectives as group, the exchange of perspectives, interests and goals between participants, and analyzing problems and interrelations between them.

- Joint fact-finding and uncertainty reduction. This seeks to develop and implement action-plans to fill knowledge gaps.

- Forging agreement. Here, the task of extension agents is to clarify positions and claims, use pressure to secure concessions, and resolve impasses.

- Communication of representatives with constituencies. This includes transferring the learning process and 'ratification' of agreement by constituencies.

- Monitoring implementation (coordinated action). This means to implement the agreements made, and create contexts for re-negotiation.

Starting from a negotiation model, considerably alters the tasks of extension agents in a participatory process. In traditional participation literature, the extension agent tends to be portrayed as a fairly neutral figure whose prime concern is to enhance communication and learning. However, in the context of negotiation it becomes more evident that an extension agent needs to have an active strategy, 
resources, and a power-base to forge sustainable agreements. Apart from a certain amount of leverage, an extension agent should possess the necessary insights and capabilities regarding social interactions, the shaping of negotiations, and the organization of learning processes.

\subsection{Organization}

EM-based agricultural extension acknowledges the value of organization in agricultural development and environmental protection. It seeks to establish a regulatory framework which ensures improvement of agriculture and environmental protection. EM emphasis is institutionalization of environmental protection into the organization of extension. This means that environmental protection activities should be incorporated into the institutional apparatus of agricultural extension organizations. It should become routine and, at times, a legally sanctioned part of its structure. EM believes that the role of the organization in agricultural development planning changes from curative and reactive to preventive, and from closed policy-making to participative policy-making where farmers and other stakeholders play a key role in organizational policies.

So far, efforts to introduce sustainable agriculture focus largely on the transformation of farms and the activities of farmers. However, these efforts reveal that the institutional frameworks in which farmers are embedded are of crucial importance for the transformation required. The institutional support for sustainable agriculture is an important new area for agricultural development. The institutional dimension of the transformation to a more sustainable society is therefore emerging rapidly as a crucial area of interest. Nowadays, few institutions support sustainability, but new networks and institutions are emerging rapidly in response to the challenge. Examples are consumer and environmental organizations, and organizations of ecological farmers (from biodynamic farmers to integrated arable farmers) [29].

Decentralization in extension organizations has been criticized. Roling [27] stated that we must admit that most extension organizations are not exactly suitable for implementing our alternative extension objectives and for a target group-oriented work practice, but he emphasized that decentralization has its own problems. So, once decentralization has been institutionalized, its own weaknesses become apparent. He concluded that it would seem that central guidance, backstopping, and control might need to accompany decentralization [27]. Leeuwis and Van den Ban [2] say that many conventional extension organizations have every reason to rethink their missions but at the same time, they should be careful not to 'throw away their babies with the bath water'. In their opinion, today there are practical challenges and theoretical reasons for changing the mission of extension organization. They propose 'learning organization' as suitable for extension, in which individuals take responsibility for their own actions, share experiences, and play an active role in solving organizational problems [2]. Some key principles for extension organization based on EM are as follows.

- Institutionalization of environmental protection in policy-making.

- Move towards consensual style of organizational structure. It is argued that relevant lessons, knowledge, and information regarding environmental protection should be shared with others in the organization.

- Try to utilize invention, innovation, and diffusion of new clean (or cleaner) technologies that demonstrate improved environmental and economic performance.

- Staff development policies must pay regard to the activities of personnel to increase production and conserve the environment.

- Problems should be seen as opportunities for learning and improvement. 
EM-based extension emphasizes the role of environmental NGOs. In a multifunction agriculture, environmental NGOs are strong stakeholders and therefore, their views and activities should be considered.

\subsection{Policy}

Scientific and technological development in agriculture has been, and still is, coupled with negative external effects, i.e. the shifting of costs to society, future generations, and nature. Therefore, one of the pending policies could be to internalize the external effects of production, shift the costs back to the agricultural units that cause the environmental problem, include the ecological perspective in all investment decision-making. According to Roling and Jiggins [29], internalizing costs by fiscal measures based on mineral bookkeeping, monitoring of pesticide use, etc., are difficult to effectuate. They argued that the development of mechanisms to make visible the impact of farming on the wider environment is essential, not only for effective fiscal measures but especially as a basis for farmer learning and anticipation. Much work is still required in this area.

On the other hand, environmental policy has mostly been designed as react-and-cure strategies with emphasis on the rehabilitation aspect. These policies symbolize a serious structural deficit: environmental protection expenditures are spent when damage to the natural environment has occurred and can no longer be denied. They are signs of a 'post-hoc' policy that reacts to damages (and must react to them) but does not or cannot prevent them. These policies usually identify a given problem too late, so that the ecosystems affected cannot survive. Preventive environmental policy, it seems, can counter the shortcomings of conventional policy. It means seeking and at last finding a better balance between the anticipatory and the reactive component within the policy action. Simonis [36] identified three factors as concomitantly relevant for preventive policy: retarding damage accumulation (of agricultural projects), accelerating technical knowledge relating to the environmental problem, and increasing the public awareness about possible environmental impacts. Acceleration of knowledge and awareness can be promoted by extension agents through a variety of approaches and methods such as Environmental Impact Assessments (EIAs) and Strategic Environmental Assessments (SEAs). In that sense, EIA and SEA can be classified as part and parcel of preventive environmental policy.

SEA and EIA are procedural tools to assess policies and can aid to the development of more sustainable policy formulation. These are highly dynamic processes and therefore subject to continuous change. SEA and EIA can be applied to agricultural and rural development plans, programs, and projects. The main purpose of SEA is to facilitate an early and systematic consideration of potential environmental impacts in strategic decision-making [37]. SEA is the optimal approach to agricultural and environmental policy assessment, because it highlights the policy-making stage so that the possible positive and negative impacts can be identified earlier. In UK, SEA is developed especially at the regional and local land use planning levels and also at the sectoral policy [37].

EIA is the process of assessing the consequences that are likely to flow from a proposed development. It is a planning and management tool for sustainable development that seeks to identify the type, magnitude, and probability of environmental and social changes that are likely to occur as direct or indirect results of a project or policy, and to design the possible mitigation procedure [38]. EIA is firmly established in planning process and impact assessments of plans in many countries.

EM theory offers an innovative method for understanding national environmental policy as embedded in changing international context, particularly given that EM sees environmental protection as a precondition for future sustainable growth [39]. This theory explicitly describes environmental improvements as being economically feasible. Indeed, entrepreneurial agents and economic/market 
dynamics are seen as playing leading roles in bringing about needed ecological changes. Also, in the context of the expectation for continued economic development, EM depicts political actors as building new and different coalitions to make environmental protection politically feasible.

Then, the integration of environmental policy goals into other policy areas of government is central to EM-based agricultural extension. It recognizes that effective environmental protection can only be achieved through a realignment of broader policy goals related to agriculture such as production, consumption, processing, and transport. In our opinion, one basic principle to be re-established in agricultural activities is that of responsibility or liability. In general, the liability principle would strengthen the anticipate-and-prevent strategy in environmental policy, and shift the technical solutions for environmental problems from ex-post to ex-ante approaches, i.e. from controlling or end-of-pipe technology towards low emission or integrated technology.

\section{CONCLUSION}

In the past, the mission of many agricultural extension organizations has been something like: 'to increase agricultural production and productivity through the transfer of relevant knowledge and information, and the offering of technical and economic advice'. Today, we recognize new challenges, problems, and developments for agricultural extension that further complicate matters. There are theoretical reasons for adapting and widening the mission of extension into something like: 'bringing about new patterns of coordination through the facilitation of learning and negotiation processes'; for example, aiming at societal goals like improved food security, poverty alleviation, ecological sustainability, food safety, increased market shares, multi-functional agriculture, etc. We can see that conventional public extension organizations are in decline, and that there is a reason to rethink seriously about their missions, activities, skills, and organizational forms. This is especially so because many have the feeling that extension is 'in crisis'.

In addition, we need various changes in the definition of extension. We must try to arrive at a mainly descriptive definition of extension to inform extension practitioners on how they can do better. In view of the need for redefinition, some senior authors in the field of extension have chosen to completely abandon the notion of 'extension' altogether. They feel that the word 'extension' has misleading connotations, and that it is practically impossible to stretch the meaning of the concept as necessary. In line with this, some authors renamed the field of extension science as 'communication and innovation studies' or 'second-order research and development' [2]. However, the point is that the professional identity of extension is changing. It can be argued that agricultural extension in Iran and developing countries should be reinvented as a professional practice and it should significantly adapt its mission, rationale, mode of operation, management, and organizational structure. This should be accompanied by conceptual changes regarding agricultural extension.

We are entering 'the age of the environment', equally; our times are called the ecological age, or the age of ecological enlightenment [40]. We should tell people what is happening to the world. We can ask ourselves whether it is even possible to develop a green theory about environment in extension. We point out that the diffusion theory based on the modernization thought appears to be neither desirable nor universally applicable because it is simply unsustainable.

The modernization theory has been used as a guiding theory for agricultural extension in Iran. However, analysis of agricultural extension policies shows that this theory has produced negative impacts such as environmental degradation and uneven development. We argued that agricultural extension theory in Iran is in crisis. We believe that EM theory could be used to theorize a green agricultural extension for Iran and developing countries. In applying EM towards the construction of a sustainable agricultural development theory, five dimensions of green extension theory including content, learning, negotiation, organization, and policy have been discussed. 


\section{REFERENCES}

[1] Roling, N., Extension Science: Information Systems in Agricultural Development, University of Cambridge: Cambridge, 1988.

[2] Leeuwis, C. \& van den Ban, A., Communication for Rural Innovation: Rethinking Agricultural Extension, Blackwell Publishing Ltd.: UK, 412 pp., 2004.

[3] Roling, N., Ascroft, J. \& Chege, F.W., The diffusion of innovations and the issue of equity in rural development. Communication Research, 3(2), pp. 155-170, 1976.

[4] Karami, E., Agricultural extension: the question of sustainable development in Iran. Journal of Sustainable Agriculture, 5(1/2), pp. 61-72, 1995.

[5] Mol, A.P.J. \& Spaargaren, G., Ecological modernisation theory in debate: a review. Environmental Politics, 9(1), pp. 17-50, 2000.

[6] Mol, A.P.J., The refinement of production: ecological modernization theory and the chemical industry, Van Arkel: Utrecht, 452 pp., 1995.

[7] Spaargaren, G. \& Mol, A.P.J., Sociology, environment and modernity: ecological modernization as a theory of social change. Society and Natural Resources, 5, pp. 323-344, 1992.

[8] Gouldson, A. \& Murphy, J., Ecological modernization and the European Union. Geoforum, 27(1), pp. 11-21, 1996.

[9] Sondergard, B., Hansen, O.E. \& Holm, J., Ecological modernisation and institutional transformations in the Danish textile industry. Journal of Cleaner Production, 12, pp. 337-352, 2004.

[10] Rezaei-Moghaddam, K., Karami, E. \& Gibson, J., Conceptualizing sustainable agriculture: Iran as an illustrative case. Journal of Sustainable Agriculture, 37(3), pp. 25-56, 2005.

[11] Iravani, H., A History of Agricultural Education and Extension in Iran, Mashhad Publishing: Mashhad, Iran, 52 pp., 1991 (in Farsi).

[12] Zamanipour, A., Agricultural Extension in the Process of Development, Ferdowsi University Press: Mashhad, 335 pp., 1994 (in Farsi).

[13] Malek-Mohammadi, I., Foundations of Agricultural Extension, University Publishing Center: Tehran, 479 pp., 1993 (in Farsi).

[14] Servaes, J., Toward a new perspective for communication and development. Communication in Development, ed. F.L. Casmir, Albex Publishing Corporation, pp. 51-85, 1991.

[15] Karami, E., Agricultural extension in development theory: some conceptual and empirical considerations. Journal of Extension Systems, 2(2), pp. 61-69, 1986.

[16] Lahsaeizadeh, A., Contemporary Rural Iran, Ashgate Publishing Ltd.: Aldershot, 348 pp., 1993.

[17] Rezaei-Moghaddam, K. \& Karami, E., Agricultural extension, poverty and sustainable agriculture: application of path analysis. The First Congress on Agricultural Extension and Education Sciences and Natural Resources of Iran, Karaj, 13-15 August, 2003 (in Farsi).

[18] Karami, E. \& Hayati, D., Rural poverty and sustainability: the case of groundwater depletion in Iran. Asian Journal of Water, Environment and Pollution, 2(2), pp. 51-61, 2005.

[19] Karami, E. \& Hayati, D., Sustainable versus conventional agriculture: measurement of attitudes. Journal of Agricultural Sciences and Natural Resources, 2(1), pp. 1-18, 1998 (in Farsi).

[20] Karami, E., Alternative agricultural extension objectives. Agricultural Progress, 68, pp. 15-23, 1993.

[21] Najafi, B., Agricultural development of Iran: major obstacles. Quarterly Journal of Agricultural Economics and Development, 6(4), pp. 245-266, 1999 (in Farsi). 
[22] Salmanzadeh, C., Sustainable agriculture and some issues in sustainability of agriculture in Iran. Proceedings of the 1st Agricultural Economics Conference of Iran, Zabol, 3-5 April, pp. 650-664, 1996 (in Farsi).

[23] Ghazinoory, S., Cleaner production in Iran: necessities and priorities. Journal of Cleaner Production, 13(8), pp. 755-762, 2005.

[24] Rezaei-Moghaddam, K., Karami, E. \& Woelfel, J., The agricultural specialists' attitudes toward alternative sustainable agricultural paradigms: a Galileo method analysis. Food, Agriculture \& Environment, 4(2), pp. 310-319, 2006.

[25] Rezaei-Moghaddam, K. \& Karami, E., A multiple criteria evaluation of sustainable agricultural development models using AHP. Environment, Development and Sustainability, in press.

[26] Evans, N., Morris, C. \& Winter, M., Conceptualizing agriculture: a critique of post-productivism as the new orthodoxy. Progress in Human Geography, 26(3), pp. 313-332, 2002.

[27] Roling, N., Alternative approaches in extension. Progress in Rural Extension and Community Development, eds G.E. Jones \& M.J. Rolls, London: John Wiley \& Sons Ltd., pp. 87-115, 1982.

[28] Huizinga, B., van Raalte, R. \& Roling, N., Five Approaches to Rural Extension, International Agricultural Center: Wageningen, 1983.

[29] Roling, N. \& Jiggins, J., The ecological knowledge system. Facilitating Sustainable Agriculture: Participatory Learning and Adoptive Management in Times of Environmental Uncertainty, Cambridge University Press: Cambridge, pp. 283-311, 1998.

[30] Janicke, M., Ecological Modernization: Innovation and Diffusion of Policy and Technology, retrieved from http://www.fu-berlin.de/ffu/akumwelt/download/jaenicke.pdf, 2000.

[31] Archambault, S., Ecological modernization of the agriculture industry in southern Sweden: reducing emissions to the Baltic Sea. Journal of Cleaner Production, 12, pp. 491-503, 2004.

[32] Sparovek, G. \& Schnug, E., Soil tillage and precision agriculture: a theoretical case study for soil erosion control in Brazilian sugar cane production. Soil \& Tillage Research, 61, pp. 47-54, 2001.

[33] Van den Hove, S., Between consensus and compromise: acknowledging the negotiation dimension in participatory approaches. Land Use Policy, 23, pp. 10-17, 2006.

[34] Young, S.C., The emergence of ecological modernisation, integrating the environment and the economy? Routledge: London, 253 pp., 2000.

[35] Leeuwis, C., Reconceptualizing participation for sustainable rural development: towards a negotiation approach. Development and Change, 31, pp. 931-959, 2000.

[36] Simonis, U.E., Ecological modernization of industrial society: three strategic elements. International Social Science Journal, 121, pp. 347-361, 1989.

[37] Kuo, N.W. \& Chiu, Y.T., The assessment of agritourism policy based on SEA combination with HIA. Land Use Policy, 23, pp. 560-570, 2006.

[38] Momtaz, S., Environmental impact assessment in Bangladesh: a critical review. Environmental Impact Assessment Review, 22, pp. 163-179, 2002.

[39] Fisher, D.R. \& Freudenburg, W.R., Ecological modernization and its critics: assessing the past and looking toward the future. Society and Natural Resources, 14, pp. 701-709, 2001.

[40] Rientjes, S., Making nature conservation modern: an analysis of developments in nature conservation policy in relation to macro-social changes: the Netherlands as a case study. Journal of Environmental Policy \& Planning, 4, pp. 1-21, 2002. 